\title{
Reproductive and Developmental Toxicology
}

National Cancer Institute

\section{Source}

National Cancer Institute. Reproductive and Developmental Toxicology. NCI Thesaurus.

Code C90448.

The branch of pharmacology that deals with the nature and effects of poisonous substances on reproduction and development. 